\title{
ANÁLISE PRELIMINAR DO PLANO INOVA EMPRESA
}

Solange Corder, Antonio Márcio Buainain e Irineu de Souza Lima Junior JEL 38 Government Policy

Palavras-chave: Política de Ciência, Tecnologia e Inovação; Política Industrial; Financiamento à Inovação; Inova Empresa

\section{Introdução}

Neste trabalho procura-se fazer uma análise do Plano Inova Empresa, lançado em março de 2013 como parte das medidas de política do governo federal destinadas a melhorar a produtividade e competitividade das empresas instaladas no país, por meio da inovação tecnológica. O Inova Empresa ampliou as experiências do PAISS e do Inova Petro, nas quais a Finep e BNDES buscavam coordenar esforços para atuar de forma integrada no financiamento a projetos e negócios com conteúdo inovador. Neste esquema, os quatro instrumentos de financiamento a PD\&I - subvenção econômica; fomento para convênios com Instituições de Ciência e Tecnologia (ICT) e projetos cooperativos; participação acionária em empresas de base tecnológica (EBT) e crédito em condições especiais - podem ser utilizados num mesmo projeto -apresentado como plano de negócio promissor e inovador. Neste modelo, cada agência administra a sua parte do recurso, ficando o cliente submetido às suas regras e procedimentos para prestação de contas.

O Inova Empresa foi lançado com uma previsão significativa de recursos que seriam aplicados pelo governo e parceiros (Sebrae, Agências Reguladoras e demais Ministérios), tendo como orientação as prioridades setoriais e estratégicas definidas no Plano Brasil Maior, a política industrial definida a partir de 2012. Naquele momento, no entanto, já era fato que a disponibilidade de recursos de natureza não reembolsável sofreria forte redução, devido ao desfalque do FNDCT em decorrência da transferência dos recursos do CT-Petro para o Fundo Social, constituído pela Lei n. 12.351/10. Tratou-se, sem dúvida, de uma tentativa oportuna de canalizar recursos para projetos de inovação de empresas, o que significava uma mudança importante em relação à orientação e os resultados observados no período anterior, durante o qual os recursos haviam sido comprometidos fundamentalmente com o financiamento de instituições científicas e tecnológicas, favorecendo projetos de natureza acadêmica, infraestrutura cientifica, construção de parte do ambiente inovador e apenas em menor medida projetos de inovação.

Mas não se pode deixar de mencionar que o crédito (financiamento reembolsável) também cresceu bastante no período que antecedeu o Inova Empresa, beneficiado principalmente pelos recursos do Plano de Sustentação do Investimento (PSI).

Para analisar a estrutura e o desempenho inicial do Inova Empresa foram revisados os principais documentos da Finep e do BNDES e os editais e chamadas públicas. Além disso, foram feitas breves consultas a gestores que estavam nas agências na época do lançamento do Plano. O fato é que a execução do Inova Empresa se deu num contexto forte de escassez de recursos financeiros, num cenário ainda mais restritivo do que aquele que estava presente na época do lançamento do Plano. Assim, a contextualização e o contraponto com os propósitos da política 
foram outro aspecto metodológico considerado nessa análise, indo além dos resultados quantitativos.

O trabalho está organizado em três seções, além da introdução e das considerações finais. Na primeira seção apresentam-se a estrutura do Plano e a perspectiva da alocação dos recursos. Na segunda seção, são analisadas a execução e a distribuição do montante aprovado através dos instrumentos. Na terceira seção é enfatizado o panorama da evolução dos recursos do FNDCT e levantados, de forma breve, alguns aspectos da problemática do financiamento a CT\&I no contexto atual.

\section{A definição do Plano Inova Empresa}

De acordo com informações do Relatório de Gestão da Finep, o Inova Empresa foi constituído a partir de um conjunto de ações articuladas entre a Casa Civil e os seguintes ministérios: MCTI, Fazenda, Saúde, Comunicações, Desenvolvimento Indústria e Comércio, Agricultura e outras instituições governamentais. A concepção do Plano baseou-se na percepção e diagnósticos, bem assentados entre os formuladores de política de CT\&I, de que o país já dispunha do conjunto de instrumentos utilizados para alavancar a inovação, e que era necessário avançar no sentido de inverter a equação até então vigente e colocar a empresa como o principal agente dos projetos de inovação financiados pelo BNDES e Finep.

Neste sentido, o Plano Inova Empresa focou na inovação nos setores prioritários, definidos no Plano Brasil Maior (a política industrial do governo federal definida em 2012), e buscava integrar os instrumentos que até então vinham sendo operados de forma descoordenada -apesar das declarações em contrário- pelo BNDES e Finep. Os diagnósticos também indicavam a dificuldade encontrada pelos agentes da política de CT\&I federal, que não contam com uma rede de agências espalhada pelo país, para alcançar as micro, pequenas e até as médias empresas, e para superar esta restrição o Inova previa a descentralização do crédito e da subvenção para as micro e pequenas empresas, por meio de convênios com a fundações estaduais de amparo à pesquisa (FAP) e outras instituições (secretarias estaduais e Instituto Euvaldo Lodi, do Sistema CNI, por exemplo).

Foram definidas 7 áreas estratégicas com perspectivas de receber financiamento no valor de $\mathrm{R} \$$ 23,5 bilhões e mais R 5 bilhões para financiar as chamadas ações transversais perfazendo um total de R \$ 28,5 bilhões. Também foram estabelecidas parcerias com outras instituições, que se comprometeram a alocar R \$ 4,4 bilhões perfazendo um montante total de R\$ 32,9 bilhões. A perspectiva, ainda, seria que cerca de $\mathrm{R} \$ 3,5$ bilhões fossem alocados com recursos do Funttel, através da Agência Reguladora de Telecomunicações, a Anatel. No Quadro 1 tem-se um detalhamento desta previsão na alocação dos recursos do governo federal, distribuídos conforme o instrumento, e o comprometimento das instituições parceiras. Nota-se que mais de $70 \%$ dos recursos correspondem a financiamento reembolsável (crédito), sendo apenas $\mathrm{R} \$ 5,4$ bilhões em financiamento sem reembolso distribuídos entre $\mathrm{R} \$ 1,2$ bilhão (4,2\%) para subvenção e $\mathrm{R} \$ 4,2$ para convênios com ICT. O montante apoiado através de renda variável (seed e venture capital) foi estabelecido em R $\$ 2,2$ bilhões.

Quadro 1. Plano Inova Empresa - Previsão de aporte de recursos do governo federal e das instituições parceiras 


\begin{tabular}{|c|c|c|c|c|c|}
\hline Fonte & Fonte & Instrumento & $\begin{array}{l}\text { Valor, em R\$ } \\
\text { bilhões }\end{array}$ & $\begin{array}{c}\text { Instrumento/ } \\
\text { Total do } \\
\text { governo e IP } \\
(\%)\end{array}$ & $\begin{array}{c}\text { Governo e } \\
\text { IP/Total (\%) }\end{array}$ \\
\hline \multirow{5}{*}{$\begin{array}{l}\text { Governo } \\
\text { Federal }\end{array}$} & \multirow[t]{5}{*}{ Finep/BNDES } & Crédito & 20,9 & $73,33 \%$ & \\
\hline & & NR & 4,2 & $14,74 \%$ & \\
\hline & & RV & 2,2 & $7,72 \%$ & \\
\hline & & Subvenção & 1,2 & $4,21 \%$ & \\
\hline & & Subtotal ID & 28,5 & $100,00 \%$ & $86,63 \%$ \\
\hline \multirow[t]{6}{*}{$\begin{array}{c}\text { Instituições } \\
\text { parceiras (IP) }\end{array}$} & $\begin{array}{l}\text { Investimento } \\
\text { das } \\
\text { concessionárias } \\
\text { (1) }\end{array}$ & ANP & 2,5 & $56,82 \%$ & \\
\hline & & SEBRAE & 1,3 & $29,55 \%$ & \\
\hline & $\begin{array}{l}\text { Investimento } \\
\text { das } \\
\text { concessionárias } \\
\text { (2) }\end{array}$ & ANEEL & 0,6 & $13,64 \%$ & \\
\hline & & Subtotal IP & 4,4 & $100,00 \%$ & $13,37 \%$ \\
\hline & & Total & 32,9 & & \\
\hline & Funttel (3) & ANATEL & 3,54 & & \\
\hline
\end{tabular}

Fonte: Elaboração própria, com base no Documento Oficial de lançamento o Plano Inova Empresa.

Dos R \$ 23,5 bilhões previstos, cerca de 24,3\% seriam destinados à área de Energia, 17,5\% para petróleo o gás, $15,3 \%$ ao complexo da saúde, 12,7\% para a cadeia agropecuária, 12,3\% ao complexo aeroespacial e defesa, 8,9\% para TICs e 8,9\% para a área socioambiental (Quadro 2).

Quadro 2. Plano Inova Empresa, ações estratégicas

\begin{tabular}{|c|c|c|c|c|}
\hline $\begin{array}{l}\text { 1. Ações } \\
\text { Estratégicas }\end{array}$ & Prioridades/Áreas & $\begin{array}{l}\text { Valor, em } \\
\text { R\$ bilhões }\end{array}$ & $\begin{array}{l}\text { Participaçã } \\
\text { o no total de } \\
\text { cada ação } \\
\text { estratégica }\end{array}$ & $\begin{array}{l}\text { Participaçã } \\
\text { o no total } \\
\text { das ações } \\
\text { estratégicas }\end{array}$ \\
\hline \multirow[t]{2}{*}{ 1.1 Energia (1) } & 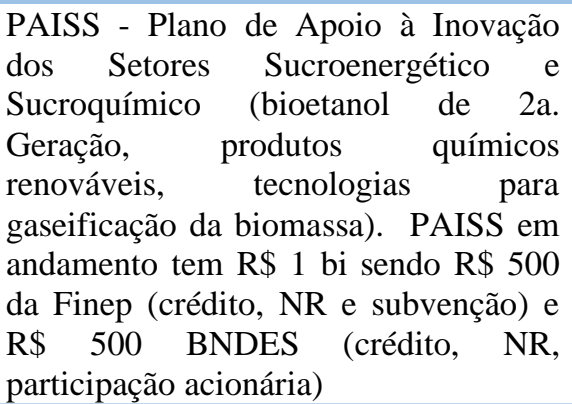 & 3,3 & $57,89 \%$ & \\
\hline & $\begin{array}{l}\text { Agropecuária e Agroindústria (redes } \\
\text { elétricas inteligentes; transmissão de } \\
\text { energia em ultra alta tensão; energias } \\
\text { alternativas (fotovoltaica } \\
\text { heliotérmica); veículos híbridos de } \\
\text { eficiência energética veicular }\end{array}$ & 2,4 & $42,11 \%$ & \\
\hline Subtotal Energia & & 5,7 & $100,00 \%$ & $24,26 \%$ \\
\hline 1.2 Petróleo e Gás (2) & $\begin{array}{l}\text { Inova Petro (pipeline de tecnologias a } \\
\text { serem desenvolvidas para áreas mais } \\
\text { intensivas em conhecimento). }\end{array}$ & 2,9 & $70,73 \%$ & \\
\hline
\end{tabular}




\begin{tabular}{|c|c|c|c|c|}
\hline & $\begin{array}{l}\text { Demais ações (tecnologias para a } \\
\text { cadeia do pré-sal: modernização e } \\
\text { implantação de centros de pesquisa; } \\
\text { novos materiais; serviços de } \\
\text { engenharia sísmica; recuperação } \\
\text { avançada de petróleo; engenharia } \\
\text { submarina) }\end{array}$ & 1,2 & $29,27 \%$ & \\
\hline \multicolumn{2}{|c|}{ Subtotal Petróleo e Gás } & 4,1 & $100,00 \%$ & $17,45 \%$ \\
\hline \multirow[t]{2}{*}{$\begin{array}{l}\text { 1.3 Complexo da } \\
\text { Saúde }\end{array}$} & $\begin{array}{l}\text { Inova Saúde (estruturação da cadeia de } \\
\text { valor em biotecnologia, síntese química } \\
\text { e biofármacos); equipamentos e } \\
\text { dispositivos médicos }\end{array}$ & 1,9 & $52,78 \%$ & \\
\hline & $\begin{array}{l}\text { Demais ações (biotecnologia; } \\
\text { investimentos em oncologia - } \\
\text { radiofármacos e células-tronco - e } \\
\text { diagnóstico molecular }\end{array}$ & 1,7 & $56,67 \%$ & \\
\hline \multicolumn{2}{|c|}{ Subtotal Complexo da Saúde } & 3,6 & $120,00 \%$ & $15,32 \%$ \\
\hline $\begin{array}{l}\text { 1.4 Cadeia } \\
\text { Agropecuária }\end{array}$ & $\begin{array}{l}\text { Insumos; mecanização e agricultura de } \\
\text { precisão; genética plantas e animais; } \\
\text { rastreamento, planejamento e controle } \\
\text { da produção agropecuária; sanidade } \\
\text { agropecuária e bem-estar animal; } \\
\text { equipamentos, tecnologia de alimentos } \\
\text { e embalagens com novas } \\
\text { funcionalidades }\end{array}$ & 3,0 & $100,00 \%$ & \\
\hline \multicolumn{2}{|c|}{ Subtotal Cadeia Agropecuária } & 3,0 & $100,00 \%$ & $12,77 \%$ \\
\hline \multirow[t]{2}{*}{$\begin{array}{l}1.5 \text { Complexo } \\
\text { Aeroespacial e } \\
\text { Defesa }\end{array}$} & $\begin{array}{l}\text { Inova defesa (veículos balísticos e não } \\
\text { tripulados; sensores e comando e } \\
\text { controle; propulsão espacial, satélites e } \\
\text { plataformas especiais; plataformas } \\
\text { tecnológicas para aeronaves mais } \\
\text { eficientes; novos materiais) }\end{array}$ & 2,4 & $82,76 \%$ & \\
\hline & Demais ações & 0,5 & $17,24 \%$ & \\
\hline \multicolumn{2}{|c|}{ Subtotal Complexo Aeroespacial e Defesa } & 2,9 & $100,00 \%$ & $12,34 \%$ \\
\hline \multirow[t]{2}{*}{$1.6 \mathrm{TICs}$} & $\begin{array}{l}\text { Tecnologias estratégicas (computação } \\
\text { em nuvem, mobilidade, computação de } \\
\text { alto desempenho, internet); Sistemas } \\
\text { para aplicações setoriais (ecossistemas } \\
\text { digitais); Softwares e serviços de TI }\end{array}$ & 0,4 & $19,05 \%$ & \\
\hline & $\begin{array}{l}\text { Demais ações (semicondutores e } \\
\text { displays); equipamentos para } \\
\text { aplicações setoriais; desenvolvimento } \\
\text { de softwares e serviços de TI; } \\
\text { desenvolvimento tecnológico para } \\
\text { banda larga e conteúdos digitais }\end{array}$ & 1,7 & $80,95 \%$ & \\
\hline \multicolumn{2}{|l|}{ Subtotal TICs } & 2,1 & $100,00 \%$ & $8,94 \%$ \\
\hline \multirow[t]{2}{*}{$\begin{array}{l}\text { 1.7 Sustentabilidade } \\
\text { Socioambiental }\end{array}$} & $\begin{array}{l}\text { Recuperação, conservação, clima e } \\
\text { biodiversidade (redução do } \\
\text { desmatamento da Amazônia); combate } \\
\text { aos efeitos de mudanças climáticas, } \\
\text { efeito estufa e poluentes; produção } \\
\text { sustentável; tratamento de resíduos, } \\
\text { efluentes, águas e solos contaminados; } \\
\text { cadeias da sociobiodiversidade }\end{array}$ & 1,3 & $61,90 \%$ & \\
\hline & $\begin{array}{l}\text { Desenvolvimento Social e Urbano: } \\
\text { mobilidade e transportes urbanos e } \\
\text { sustentáveis; construções es e } \\
\text { infraestrutura urbana sustentável; } \\
\text { reciclagem de resíduos e saneamento }\end{array}$ & 0,8 & $38,10 \%$ & \\
\hline
\end{tabular}




\begin{tabular}{|c|c|c|c|}
\hline Subtotal Sustentabilidade Socioambiental & 2,1 & $100,00 \%$ & $8,94 \%$ \\
\hline Subtotal geral (1) & 23,5 & - & $100,00 \%$ \\
\hline
\end{tabular}

Fonte: Elaboração própria com base no Documento Oficial do Plano Inova Empresa

(1) O PAISS foi lançado em março de 2011 e já contava com R\$ 1 bilhão em execução na época do lançamento do Inova Empresa.

(2) O Inovapetro foi lançado em13/08/2013 e já contava com R\$ 3,0 bi em execução em 2013 (R \$ 1,5 da Finep e R\$ 1,5 do BNDES).

Nas ações transversais, conforme apresentado no Quadro 3, dos R 5 bilhões previstos, cerca de 20\% (R\$ 1 bilhão) seriam recursos do PSI para crédito destinado a financiar projetos de engenharia (produto e processo) e aproximadamente 36,4\% ( $\mathrm{R} \$ 1,82$ bilhão) seriam recursos para micro, pequenas e médias (MPME), aplicados por meio dos seguintes instrumentos: subvenção a ser administrada pelas FAP e outros agentes credenciados, por meio do Tecnova (R\$ 350 milhões - 19,2\% do total); crédito aplicado de forma descentralizada por bancos e agências estaduais, através do Inovacred ( $\mathrm{R}$ \$ 1,2 bilhão - 66\% do total); venture capital, através do Criatec II e III (R\$ 220 milhões - 12\% do total) e recursos não reembolsáveis destinados a entidades estaduais para Capacitação de MPME (R 50 milhões - 2,7\% do total).

\section{Quadro 3. Plano Inova Empresa, ações transversais}

\begin{tabular}{|c|c|c|c|c|c|}
\hline \multicolumn{2}{|c|}{ Ações transversais } & Descrição & \multirow{2}{*}{$\begin{array}{l}\text { Valor, } \\
\text { em R\$ } \\
\text { bilhões }\end{array}$} & \multirow{2}{*}{$\begin{array}{c}\text { Percentual } \\
\text { no total de } \\
\text { cada ação } \\
\text { transversal } \\
50,00 \%\end{array}$} & \multirow{2}{*}{$\begin{array}{l}\text { Agência e } \\
\text { Percentual } \\
\text { no total das } \\
\text { ações } \\
\text { transversais } \\
\text { Finep }\end{array}$} \\
\hline \multirow[t]{3}{*}{$\begin{array}{l}\text { Produto e } \\
\text { processo }\end{array}$} & \multirow[t]{2}{*}{$\begin{array}{l}\text { P\&D, Inovação } \\
\text { incremental, } \\
\text { Engenharia de } \\
\text { Produto } \\
\text { Processo }\end{array}$} & $\begin{array}{l}\text { PSI Inovação } \text { (apoio a } \\
\text { investimentos em P\&D, ao } \\
\text { desenvolvimento de inovações } \\
\text { em produto, processo e } \\
\text { marketing }\end{array}$ & & & \\
\hline & & $\begin{array}{l}\text { PSI Proengenharia (apoio a } \\
\text { projetos de engenharia no setor } \\
\text { automotivo, bens de capital, } \\
\text { defesa, aeronáutico, } \\
\text { aeroespacial, nuclear, petróleo e } \\
\text { gás e petroquímico }\end{array}$ & 0,50 & $50,00 \%$ & BNDES \\
\hline & \multicolumn{2}{|c|}{$\begin{array}{l}\text { Subtotal Desenvolvimento P\&D, Inovação } \\
\text { Incremental, Engenharia de Produto e Processo }\end{array}$} & 1,00 & $100,00 \%$ & $19,84 \%$ \\
\hline \multirow[t]{5}{*}{ MPME } & \multirow{4}{*}{$\begin{array}{l}\text { Descentralização } \\
\text { para Micro e } \\
\text { Pequena } \\
\text { Empresa }\end{array}$} & $\begin{array}{l}\text { Tecnova (descentralização de } \\
\text { subvenção econômica para } \\
\text { MPEs) }\end{array}$ & 0,35 & $19,23 \%$ & Finep \\
\hline & & $\begin{array}{l}\text { Inovacred (descentralização do } \\
\text { crédito por bancos e agências } \\
\text { estaduais) }\end{array}$ & 1,20 & $65,93 \%$ & Finep \\
\hline & & $\begin{array}{l}\text { Criatec II e III (fundos de } \\
\text { capital semente) }\end{array}$ & 0,22 & $12,09 \%$ & BNDES \\
\hline & & $\begin{array}{l}\text { Extensionismo (capacitação de } \\
\text { MPEs por entidades estaduais) }\end{array}$ & 0,05 & $2,75 \%$ & Finep \\
\hline & \multicolumn{2}{|c|}{$\begin{array}{l}\text { Subtotal Descentralização para Micro e Pequena } \\
\text { Empresa }\end{array}$} & 1,82 & $100,00 \%$ & $36,11 \%$ \\
\hline $\begin{array}{l}\text { Infraestrutura } \\
\text { inovação }\end{array}$ & $\begin{array}{l}\text { Infraestrutura } \\
\text { para inovação }\end{array}$ & 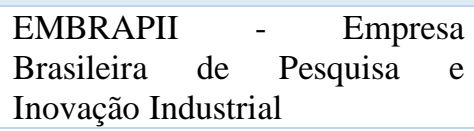 & 1,00 & $45,05 \%$ & Finep \\
\hline
\end{tabular}




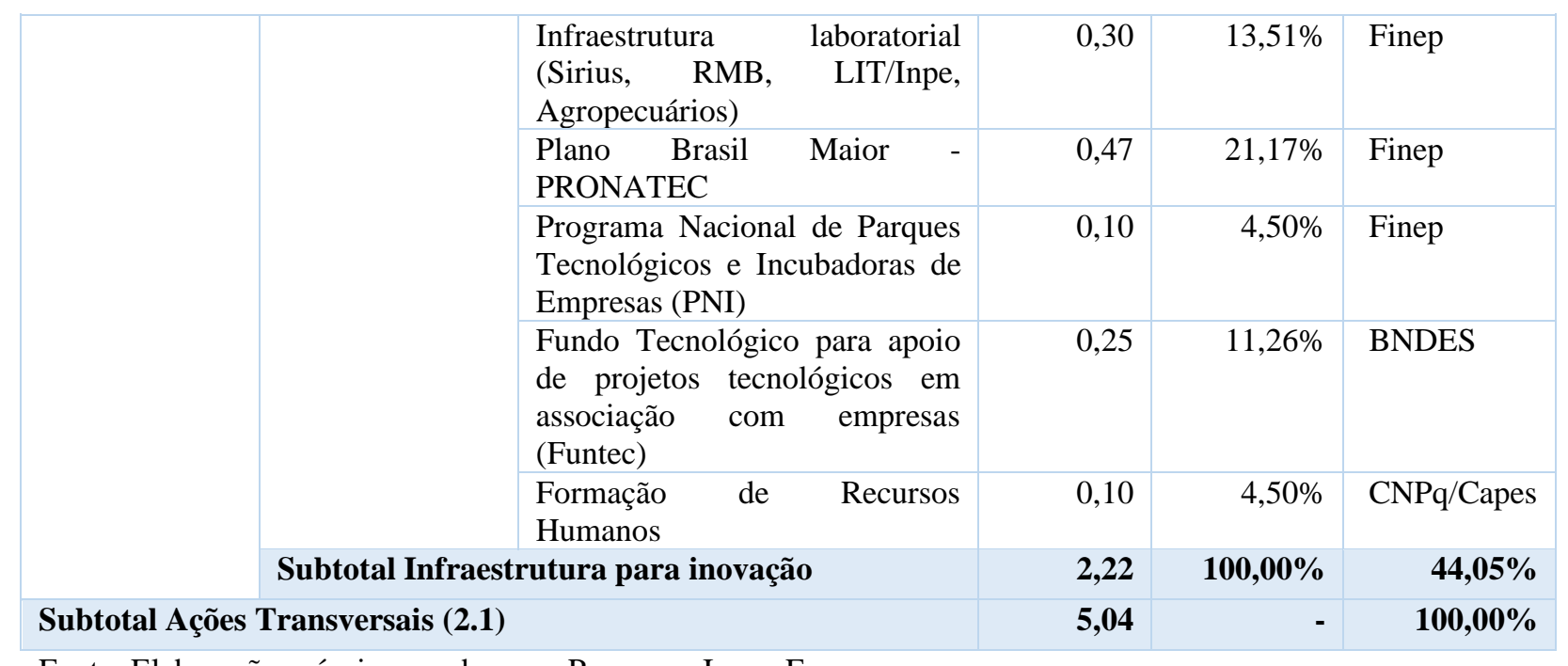

Fonte: Elaboração própria, com base no Programa Inova Empresa

Dos cerca de 44\% (R\$ 2,2 bilhões) em recursos não reembolsáveis para infraestrutura de inovação, 45\% seriam destinados para a Empresa Brasileira de Pesquisa e Inovação Industrial (Embrapii) (R\$ 1 bilhão); 13,5\% para Laboratórios Nacionais (R\$ 30 milhões); 21\% para 0 Ministério da Educação, a ser aplicado no Programa Nacional de Acesso ao Ensino Técnico e ao Emprego (Pronatec), com o intuito de ampliar o número de vagas nos cursos técnicos; 4,5\% para o Programa Nacional de Parques e Incubadoras de Empresas (R\$ 10 milhões); 11,16\% para o Funtec, voltado para o financiamento de projetos cooperativos ICT-empresa; 4,5\% para formação de recursos humanos, via CNPq (R\$ 10 milhões).

De forma resumida, o Plano Inova Empresa previu a seguinte alocação de recursos: 
Figura 1. Distribuição dos recursos do Inova Empresa, segundo as ações e os parceiros

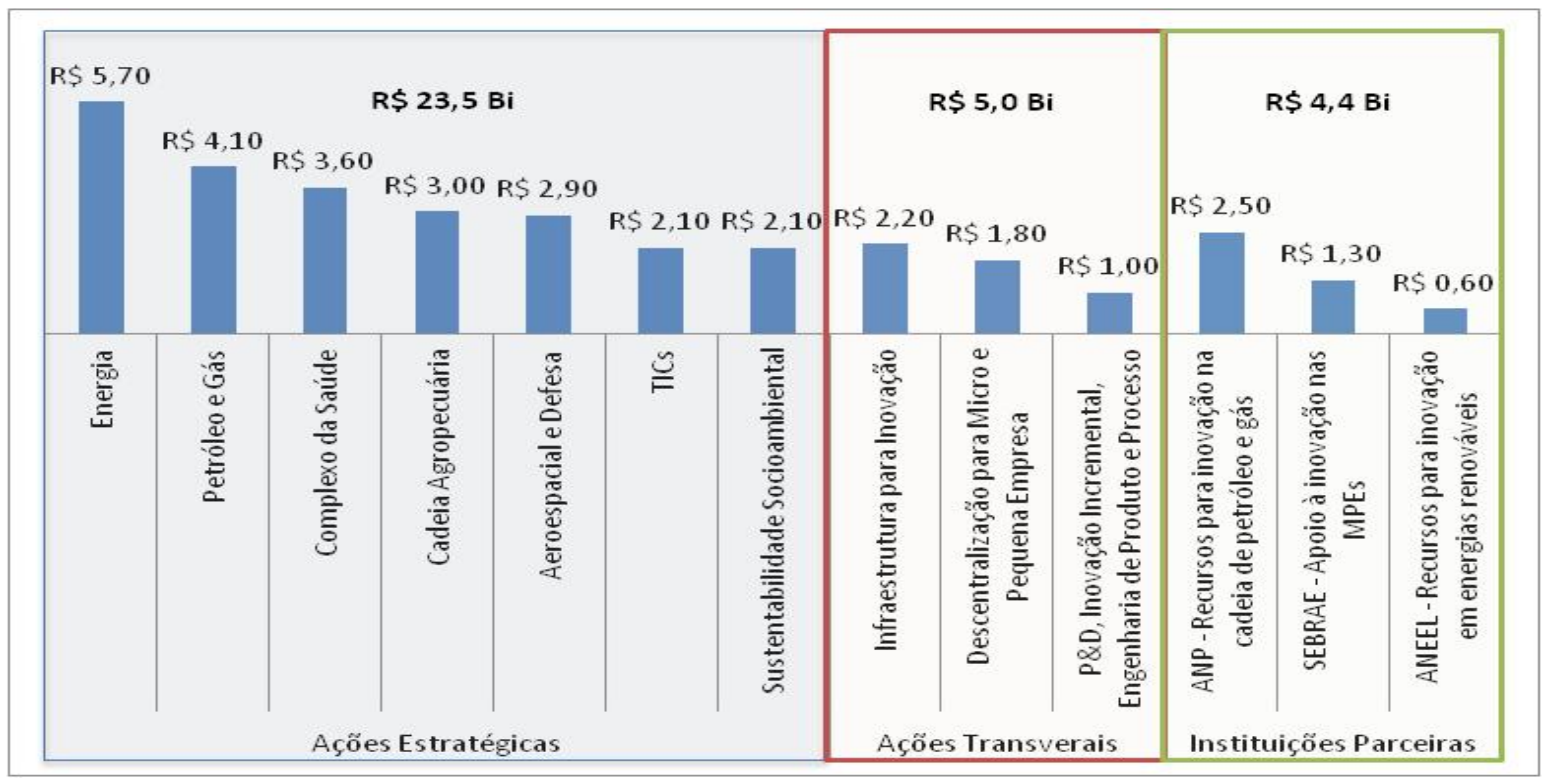

Fonte: Elaborado pela CNI

Os recursos deveriam ser alocados entre 2014 e 2015, mas logo no início o prazo foi estendido em virtude da dimensão do plano, das diversas etapas para aprovação dos projetos e da própria dificuldade relacionada à liberação dos recursos. Naturalmente que esta complexidade era já conhecida pelos operadores, e o anúncio pela Presidente da República de que estava destinando $\mathrm{R} \$ 32,9$ bilhões para financiar a inovação nas empresas, em um prazo tão curto, tinha clara motivação política. No mesmo sentido, em termos de comprometimento, a meta inicial do Plano foi ampliada, mas os desembolsos não têm sido feitos e a meta já está comprometida. O agravamento da crise econômica e política parece explicar as dificuldades de pagar o montante comprometido: do lado da oferta, o BNDES e a Finep colocaram um freio na expansão devido às incertezas em relação à disponibilidade de recursos para o PSI, e do lado da demanda muitas empresas decidiram paralisar e ou desacelerar investimentos programados e mesmo em execução, deixando de sacar valores já previamente autorizados e que não geram custos antes do saque.

\section{Inova Empresa: instrumentos de financiamento e recursos}

A forma de operacionalizar os recursos reembolsável, não reembolsável e renda variável/investimentos em venture e seed capital é diferenciada. Para submeter uma proposta de captação de recursos por meio de crédito, por exemplo, as empresas comunicam-se diretamente com as agências. Como regra, os recursos não reembolsáveis são alocados de modo competitivo, em geral chamadas públicas e editais, ainda que as agências possam usar carta-convite ou encomenda, para uma ou mais instituições, segundo o conteúdo e prioridade do projeto ${ }^{1}$. No caso do Inova Empresa, o caminho competitivo foi o utilizado para a seleção de todos os projetos, sendo a definição dos 
instrumentos feita pelas próprias agências em função da natureza das atividades previstas e necessárias no plano de negócios apresentado pelas empresas.

Entre 2013 e 2014 foram lançados 21 editais e chamadas públicas, incluindo o PAISS, o Inova-Petro e o lançamento do Fundo de Investimento em Participações (FIP Inova Empresa) ${ }^{2}$. O último edital data de novembro de $2015^{3}$. Neste conjunto de editais e chamadas foi comprometido um montante de aproximadamente $\mathrm{R} \$ 22$ bilhões, cerca de $67 \%$ do inicialmente previsto, sendo $\mathrm{R} \$ 12,7$ bilhões pela Finep, R\$ 8,4 bilhões pelo BNDES e pouco mais de R 1 bilhão pelos demais parceiros.

De acordo com o Relatório de Gestão da Finep (2013), no ano de 2013 foram ofertados R \$18,12 bilhões, dos quais R $\$ 11,2$ (cerca de 62\%) provenientes da Finep. Esse valor foi bem inferior à demanda, que chegou a $\mathrm{R} \$$ 68,2 bilhões provenientes de mais de 2.500 empresas e 200 instituições de pesquisa. Ainda em 2013 foi lançado o Fundo de Investimento em Participações (FIP-Inova Empresa), com uma dotação inicial de R\$ 200 milhões para investimento em empresas com elevado risco tecnológico. Em 2014 a demanda foi de mais R\$30,5 bilhões, perfazendo um valor total nos dois anos (2013 e 2014) de R\$ 98,7 bilhões. Em 2014, 215 empresas e 22 instituições de pesquisa demandaram recursos via Inova Empresa, elevando a demanda total do período para 2.715 empresas e 233 instituições de pesquisa. Em resposta a esta demanda, Finep e BNDES elevaram o volume total de recursos de R 28,5 bilhões para R $\$$ 51,31 bilhões, e até o final de 2014 R \$35,4 bilhões haviam sido contratados (69\%), conforme apresentado na Tabela 1 (Finep, Relatório de Gestão, 2014). Trata-se, sem dúvida, de um montante expressivo e inédito alocado para projetos com conteúdo inovador no país, e todo o processo mereceria um acompanhamento cuidadoso para avaliar os resultados diretos e indiretos do financiamento, e ponderar os ganhos efetivos que validam (ou não) as condições especiais e o ônus assumido pelo Tesouro.

\footnotetext{
${ }^{1}$ Essa regra é seguida pela Finep para alocar os recursos do FNDCT. No caso do Funtec, a operação é direta, exigindo consulta prévia. Isso porque parte dos lucros do Banco, que são destinados a programas e ações de natureza social.

${ }^{2}$ No âmbito do Programa Inovar, foi realizada a chamada para seleção de administração do fundo FIP Inova Empresa, criado em meados de 2013. Com o fundo FIP, a Finep pode adquirir participação societária. Para tanto disponibilizou R\$ 500 milhões, sendo 200 de capital próprio (dividendos de ações recebidos da Telebrás e BNB) e 300 sob a forma de empréstimo do Funttel, voltados para operações em empresas do setor de telecomunicações (Relatório de Gestão, 2014).

${ }^{3}$ Edital do Plano de Desenvolvimento e Inovação da Indústria Química (PADIQ).
} 
Tabela 1. Valor contratado no âmbito do Plano Inova Empresa, por área

Em R\$ bilhões

\begin{tabular}{|c|c|c|c|c|c|c|c|c|c|c|}
\hline \multirow[t]{2}{*}{ Área } & \multirow[t]{2}{*}{ Ações } & \multicolumn{3}{|c|}{ Carteira Total } & \multicolumn{3}{|c|}{ Contratado } & \multicolumn{3}{|c|}{ A contratar } \\
\hline & & $\begin{array}{c}\text { Tot } \\
\text { al }\end{array}$ & $\begin{array}{c}\text { BNDE } \\
\text { S* }^{*}\end{array}$ & $\underset{* *}{\text { FINEP }}$ & $\begin{array}{c}\text { Tot } \\
\text { al }\end{array}$ & $\begin{array}{c}\text { BNDE } \\
\text { S* }\end{array}$ & $\underset{* *}{\text { FINEP }}$ & $\begin{array}{c}\text { Tot } \\
\text { al }\end{array}$ & $\begin{array}{l}\text { BNDE } \\
\text { S* }\end{array}$ & $\underset{* *}{\text { FINEP }}$ \\
\hline \multirow[t]{3}{*}{ Energia } & PAISS & 4,28 & 2,58 & 1,70 & 4,28 & 2,58 & 1,70 & - & - & - \\
\hline & $\begin{array}{l}\text { Inova } \\
\text { Energia }\end{array}$ & 2,70 & 2,30 & 0,40 & 0,27 & 0,04 & 0,23 & 2,43 & 2,26 & 0,17 \\
\hline & $\begin{array}{l}\text { Demais } \\
\text { Ações }\end{array}$ & 3,59 & 1,00 & 2,60 & 3,09 & 0,72 & 2,38 & 0,50 & 0,28 & 0,22 \\
\hline \multirow[t]{3}{*}{$\begin{array}{l}\text { Petróleo e } \\
\text { Gás }\end{array}$} & $\begin{array}{l}\text { Inove Petro } \\
\text { ( } 1^{\circ} \text { edital) }\end{array}$ & 0,14 & 0,03 & 0,11 & 0,10 & 0,03 & 0,07 & 0,04 & - & 0,04 \\
\hline & $\begin{array}{l}\text { Inova Petro } \\
\left(2^{\circ} \text { edital }\right)\end{array}$ & - & - & - & - & - & - & - & - & - \\
\hline & $\begin{array}{l}\text { Demais } \\
\text { Ações }\end{array}$ & 2,51 & 0,60 & 1,91 & 2,13 & 0,59 & 1,54 & 0,38 & 0,01 & 0,37 \\
\hline \multirow[t]{3}{*}{$\begin{array}{l}\text { Complexo } \\
\text { da Saúde }\end{array}$} & $\begin{array}{l}\text { Inova Saúde } \\
\text { - Fármacos }\end{array}$ & 1,27 & - & 1,27 & 1,20 & - & 1,20 & 0,08 & - & 0,08 \\
\hline & $\begin{array}{l}\text { Inova Saúde } \\
- \\
\text { Equipamento } \\
\text { s }\end{array}$ & 0,37 & 0,16 & 0,22 & 0,13 & 0,04 & 0,09 & 0,25 & 0,12 & 0,13 \\
\hline & $\begin{array}{l}\text { Demais } \\
\text { Ações }\end{array}$ & 4,13 & 2,51 & 1,63 & 3,52 & 1,97 & 1,55 & 0,62 & 0,53 & 0,08 \\
\hline \multirow{2}{*}{$\begin{array}{c}\text { Complexa } \\
\text { Aeroespacial } \\
\text { e Defesa }\end{array}$} & $\begin{array}{l}\text { Inova } \\
\text { Aerodefesa }\end{array}$ & 1,90 & 1,23 & 0,67 & 0,17 & 0,01 & 0,16 & 1,74 & 1,22 & 0,52 \\
\hline & $\begin{array}{l}\text { Demais } \\
\text { Ações }\end{array}$ & 3,48 & 2,66 & 0,82 & 3,35 & 2,66 & 0,69 & 0,13 & - & 0,13 \\
\hline \multirow[t]{2}{*}{ TICs } & $\begin{array}{l}\text { Inova } \\
\text { Telecom }\end{array}$ & 1,05 & 0,75 & 0,30 & 0,12 & - & 0,12 & 0,93 & 0,75 & 0,18 \\
\hline & $\begin{array}{l}\text { Demais } \\
\text { Ações }\end{array}$ & 5,60 & 3,69 & 1,90 & 4,34 & 3,37 & 0,96 & 1,26 & 0,32 & 0,94 \\
\hline \multirow{2}{*}{$\begin{array}{l}\text { Sustentabilid } \\
\text { ade } \\
\text { Socioambien } \\
\text { tal }\end{array}$} & $\begin{array}{l}\text { Inova } \\
\text { Sustentabilid } \\
\text { ade }\end{array}$ & 1,38 & 0,79 & 0,58 & 0,26 & 0,24 & 0,02 & 1,11 & 0,55 & 0,56 \\
\hline & $\begin{array}{l}\text { Demais } \\
\text { Ações }\end{array}$ & 3,21 & 0,56 & 2,64 & 1,89 & 0,53 & 1,36 & 1,32 & 0,04 & 1,28 \\
\hline \multirow{3}{*}{$\begin{array}{c}\text { Cadeia } \\
\text { Agropecuári } \\
\text { a }\end{array}$} & Inova Agro & 1,08 & 0,59 & 0,49 & 0,35 & 0,24 & 0,11 & 0,73 & 0,35 & 0,38 \\
\hline & $\begin{array}{l}\text { PAISS } \\
\text { Agrícola }\end{array}$ & 1,09 & 0,80 & 0,29 & 0,40 & 0,40 & - & 0,69 & 0,40 & 0,29 \\
\hline & $\begin{array}{l}\text { Demais } \\
\text { Ações }\end{array}$ & 1,74 & 0,15 & 1,59 & 1,33 & 0,08 & 1,26 & 0,41 & 0,07 & 0,34 \\
\hline \multirow[t]{3}{*}{$\begin{array}{c}\text { Ações } \\
\text { Transversais }\end{array}$} & $\begin{array}{l}\text { Inovação e } \\
\text { Engenharia }\end{array}$ & 9,56 & 5,38 & 4,19 & 6,35 & 3,55 & 2,81 & 3,21 & 1,83 & 1,38 \\
\hline & $\begin{array}{l}\text { Descentraliza } \\
\text { ção para } \\
\text { MPEs }\end{array}$ & 1,48 & 0,31 & 1,17 & 1,47 & 0,30 & 1,17 & 0,01 & 0,01 & - \\
\hline & $\begin{array}{l}\text { Infraestrutura } \\
\text { para } \\
\text { Inovação }\end{array}$ & 0,73 & 0,54 & 0,19 & 0,64 & 0,47 & 0,17 & 0,09 & 0,07 & 0,02 \\
\hline \multicolumn{2}{|c|}{ Total } & $\begin{array}{r}51,3 \\
1\end{array}$ & 26,62 & 24,69 & $\begin{array}{r}35,4 \\
0\end{array}$ & 17,80 & 17,60 & $\begin{array}{r}15,9 \\
1\end{array}$ & 8,82 & 7,10 \\
\hline \multicolumn{2}{|c|}{ Subtotal editais conjuntos } & $\begin{array}{r}17,4 \\
8\end{array}$ & 10,08 & 7,41 & 9,39 & 4,34 & 5,05 & 8,09 & 5,73 & 2,36 \\
\hline
\end{tabular}

OBS: Data base das informações: 30/12/2014 (BNDES) e 12/12/2014 (Finep)

*Trata-se de valor total do projeto. Desses, na média, 35\% correspondem à contrapartida das empresas/ICT

** Trata-se de valor total do projeto. Desses, na média, 32\% correspondem à contrapartida das empresas/ICT

Fonte: GAPR. Ver Finep, Relatório de Gestão, 2014. 
Para algumas áreas, porém, o valor contratado foi pouco representativo, caso do Inova Energia, Aerodefesa e Sustentabilidade, com algo em torno de 10\% dos projetos contratados, e o Inova Saúde Equipamentos Médicos, Inova Agro e Paiss, com cerca de 35\% dos projetos contratados.

A tabela 2 apresenta os projetos e o perfil das fontes de recursos: dos R\$ 35,4 bilhões contratados, $86 \%$ são recursos reembolsáveis, 8\% renda variável e 6\% não reembolsável (incluindo a subvenção). É evidente o desequilíbrio entre as fontes, fato que influencia a seleção dos projetos e restringe a viabilidade de propostas que envolvam inovações mais radicais. Isso por conta dos elevados custos financeiros envolvidos no financiamento com base no crédito. Ainda que não se tenha informações mais detalhadas sobre o perfil dos projetos aprovados, é razoável supor que se tratem de projetos de modernização, que incorporam atividades de P\&D para adaptar e ajustar tecnologia e modelos de negócios já conhecidos, e que configuram inovações para as empresas demandantes e para o mercado nacional.

Tabela 2. Desempenho por instrumento, Finep e BNDES

\begin{tabular}{|c|c|c|c|c|c|c|}
\hline \multirow[t]{2}{*}{ Instrumento } & \multicolumn{3}{|c|}{ Contratado } & \multicolumn{3}{|c|}{ A contratar } \\
\hline & Total & BNDES* & FINEP** & Total & BNDES* & FINEP** \\
\hline Crédito & 30,47 & 14,47 & 16,00 & 13,42 & 7,80 & 5,62 \\
\hline Renda Variável & 2,67 & 2,59 & 0,08 & 1,00 & 0,50 & 0,50 \\
\hline Não Reembolsável & 1,23 & 0,74 & 0,49 & 0,62 & 0,51 & 0,11 \\
\hline Subvenção & 1,03 & - & 1,03 & 0,87 & - & 0,87 \\
\hline Total & 35,40 & 17,80 & 17,60 & 15,91 & $\mathbf{8 , 8 1}$ & 7,10 \\
\hline
\end{tabular}

OBS: Data base das informações: 30/12/2014 (BNDES) e 12/12/2014 (Finep)

*Trata-se de valor total do projeto. Desses, na média, 31\% correspondem à contrapartida das empresas/ICT

** Trata-se de valor total do projeto. Desses, na média, 32\% correspondem à contrapartida das empresas/ICT

Fonte: GAPR. Ver Finep, Relatório de Gestão, 2014.

Nota-se que o Inova Empresa ficou concentrado, em função do perfil do financiamento, em empresas de maior porte, capazes de disponibilizar contrapartidas financeiras expressivas e de assegurar garantias aos empréstimos obtidos ${ }^{4}$. O Inovacred, que favorece empresas de menor porte com financiamentos de valor inferior a R\$ 1 milhão (que era o valor mínimo financiado pelo Programa de Crédito da Finep), somado ao Tecnova, programa de subvenção, perfazem uma disponibilidade de recursos de $\mathrm{R} \$ 1$ bilhão, montante bastante reduzido em relação àquele destinado às empresas de maior porte e estrutura financeira. ${ }^{5}$

\footnotetext{
${ }^{4}$ Ao longo do tempo, o Inovacred passou por mudanças, dentre elas a ampliação dos limites de crédito para os agentes, a simplificação dos processos e o aumento do valor das operações e do spread. Os modelos de relatórios foram simplificados e os custos operacionais também foram diferenciados, de acordo com a região. Para detalhes sobre as condições atuais do Programa, ver http://www.finep.gov.br/apoio-e-financiamento-externa/programas-elinhas/descentralizacao/inovacred

${ }^{5} \mathrm{O}$ Programa Tecnova representou uma nova roupagem para as ações de subvenção, descentralizadas até então aos estados com o apoio das Fundações de Amparo à Pesquisa através do PAPPE-Inovação, com vistas a apoiar novos negócios de micro e pequenas empresas (MPME). O Tecnova permitiu diversificar o número de agentes credenciados para operar os recursos. Os parceiros foram selecionados em 20 unidades da federação e, até o final de 2014, foram aprovados 382 projetos. O mesmo conjunto de empresas de pequeno e médio porte parece ter sido melhor atendido pelo
} 
Ainda que seja muito cedo para avaliar o Inova Empresa, é possível afirmar que o desequilíbrio entre os recursos alocados sob a forma de crédito e sob a forma de subvenção revela que o Inova Empresa não se distingue das linhas de financiamento que vinham sendo disponibilizadas no âmbito do Plano de Sustentação do Investimento (PSI), o programa de apoio aos investimentos operacionalizado pelo BNDES, que financiou até dezembro de 2015 investimentos com taxas de juros especiais, subsidiadas pelo Tesouro Nacional ${ }^{6}$. As condições atuais para a execução dos contratos de crédito não são as mais confortáveis, tanto para a Finep como para o BNDES, dada a elevação recente dos custos financeiros ${ }^{7}$.

O problema é que não há perspectivas de mudança no perfil da distribuição entre os instrumentos de financiamento, dadas as condições atuais do FNDCT. Isto é, os recursos para financiamento não reembolsáveis são exíguos e as fontes do FNDCT têm sido alteradas elevando-se o percentual de participação do Tesouro com o intuito de substituir a queda das fontes dos fundos setoriais, mais precisamente, do CT-Petro.

\section{A Evolução dos recursos do FNDCT}

Uma análise geral do orçamento do FNDCT é suficiente para revelar alguns efeitos negativos imediatos da perda do CT-Petro ("Compensações Financeiras pela Exploração de Petróleo ou Gás Natural”, Fonte 142) sobre ações do Inova Empresa e da Finep em geral, confirmando a afirmativa acima. Conforme mencionado, os recursos do CT-Petro foram destinados ao Fundo Social ${ }^{8}$, em meio às perspectivas abertas pela descoberta do pré-sal. Independente do volume de recursos que se esperava amealhar para o Fundo Social, o fato é que a transferência do CT-Petro para um fundo com governança própria, cujos recursos são compartilhados com outras finalidades, impôs perda imediata significativa ao FNDCT e gerou uma enorme instabilidade para o Sistema de CT\&I. Não é demais lembrar que no período 1999-2012 o CT-Petro respondeu por cerca de 38\% dos recursos do FNDCT. Mais precisamente, a transferência dos recursos do CT- Petro para o Fundo Social significou um corte de quase $40 \%$ dos recursos do FNDCT a partir de 2014.

O orçamento previsto para 2016, segundo os projetos de lei anuais (PLOA), foi inferior ao do ano de 2011. Apesar de 2015 ter representado um crescimento nominal em relação aos demais

Inovacred, uma vez que 21 estados passaram a ser atendidos pelo programa por meio de 15 agentes. Foram 69 projetos aprovados até dezembro de 2012.

${ }^{6}$ O PSI favoreceu também a Finep, pois ela capta junto ao BNDES parte do funding para os empréstimos que realiza.

${ }^{7}$ A taxa de juros de longo prazo (TJLP) com a qual essas agências operam é fixada trimestralmente e no período de 2013 a 2014 ficou estável em 5\% ao ano (aa). Em 2015 o aumento foi de 0,5\% a cada trimestre, chegando a 7,0\% em dezembro. No primeiro trimestre de 2016 houve novo aumento, para $7,5 \%$ mas este valor foi mantido constante até setembro. Ainda assim, continua sendo um custo atrativo às empresas, dado que a Selic, que é a taxa do mercado nacional, encontra-se 14,25\% (levantamento realizado em junho de 2016).

${ }^{8}$ Constituído em 2010 pela Lei n. 12.351. A destinação dos recursos do petróleo está prevista na Lei n. 12.858 de 09/09/2013. A proposta do Fundo Social é "(...) constituir fonte de recursos para o desenvolvimento social e regional, na forma de programas e projetos nas áreas de combate à pobreza e de desenvolvimento: I - da educação; II - da cultura; III - do esporte; IV - da saúde pública; V - da ciência e tecnologia; VI - do meio ambiente; VII - de mitigação e adaptação às mudanças climáticas". 
anos analisados, houve cortes expressivos que impediram a execução orçamentária total deste volume de recursos. 
Figura 2. Evolução da proposta orçamentária para o FNDCT - PLOA 2011-2016

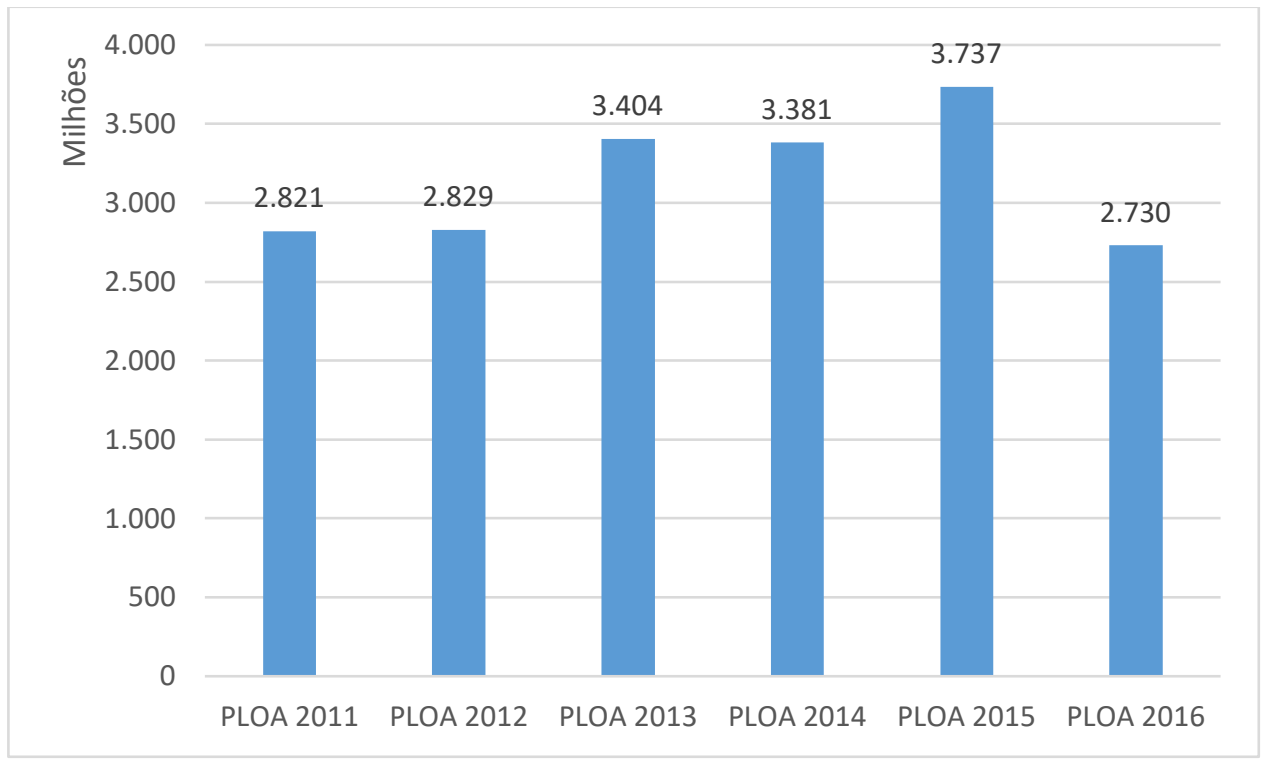

Fonte: Ministério do Planejamento

A participação das fontes que compõem o FNDCT variou durante estes anos. A partir de 2013, a principal fonte do FNCT passou a ser a 172, “Outras Contribuições”, que é composta com recursos do Fundo Verde-Amarelo (FVA). No ano de 2013 ela representou quase 49\% dos recursos totais do FNDCT. Em 2014, cerca de 76\% do fundo foram recursos do FVA. Em 2015 entraram mais recursos do Tesouro ("Recursos Ordinários do Tesouro" - Fonte 100), o que explica o crescimento da dotação orçamentária prevista (porém não executada). Em 2016, no entanto, quase não houve recursos do Tesouro e o FVA voltou a compor mais de $80 \%$ dos recursos do FNDCT (Tabela 3)

Tabela 3. Participação das principais fontes do FNDCT, segundo o Projeto de Lei Orçamentária (PLOA), 2011-2016

\begin{tabular}{|lrrrrrr|}
\hline Fonte & PLOA & \multicolumn{1}{c}{ PLOA } & \multicolumn{1}{c}{ PLOA } & \multicolumn{1}{c|}{ PLOA } & PLOA 2015 & PLOA 2016 \\
& $\mathbf{2 0 1 1}$ & \multicolumn{1}{c|}{$\mathbf{2 0 1 2}$} & $\mathbf{2 0 1 3}$ & $\mathbf{2 0 1 4}$ & & \\
\hline Fonte 142 & $47,86 \%$ & $47,75 \%$ & $38,04 \%$ & $0,00 \%$ & $0,00 \%$ & $0,00 \%$ \\
\hline Fonte 172 & $42,85 \%$ & $42,75 \%$ & $48,81 \%$ & $75,86 \%$ & $59,30 \%$ & $80,41 \%$ \\
\hline Fonte 100 & $1,32 \%$ & $1,06 \%$ & $1,45 \%$ & $5,43 \%$ & $32,56 \%$ & $0,02 \%$ \\
\hline
\end{tabular}

Fonte: Ministério do Planejamento

Observando-se a diferença entre os valores orçamentários, isto é, aprovados em lei (Lei de Orçamento Anual - LOA), e os valores empenhados, isto é, o valor que efetivamente é permitido gastar, a situação para 2015 já se mostrava bastante complicada. Embora a LOA tenha compensado a saída do CT-Petro com recursos de outras fontes, o valor empenhado até o final do primeiro semestre (R\$ 441 milhões) não chegou a 12\% do valor total do orçamento para o ano, refletindo contingenciamento de recursos. Ou seja, o Tesouro aprova, mas não entrega. (Figura 3) 
Figura 3. FNDCT. Evolução dos valores definidos anualmente em lei e empenhados, 1999julho 2015, em R\$ correntes

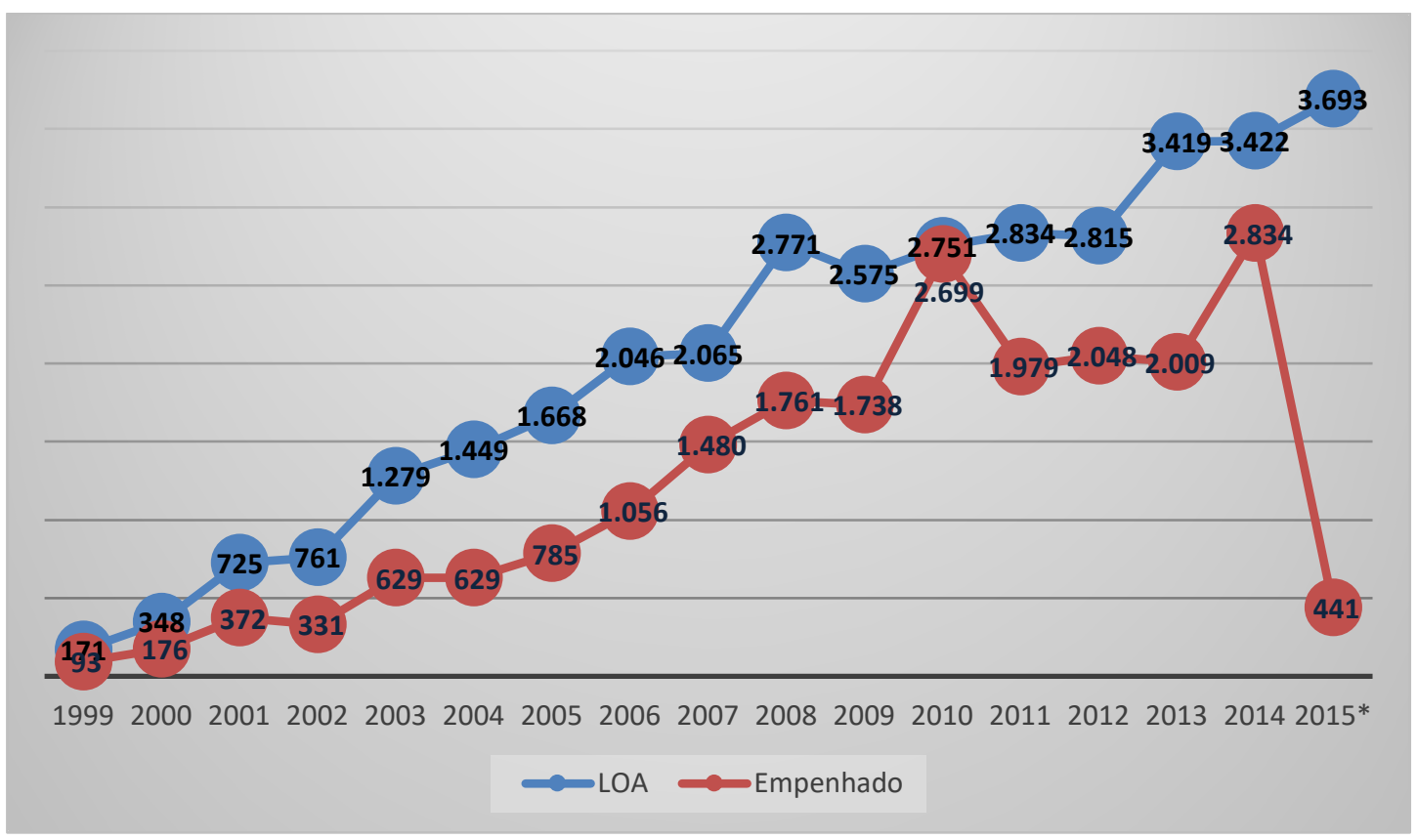

Fonte: Siga Brasil. (*) Informações levantadas em 16 de julho de 2015

Analisando-se a evolução do orçamento do FNDCT nas operações especiais, que envolvem os recursos para infraestrutura, ações estratégicas, subvenção e investimento em venture capital, nota-se que as dificuldades de cumprir com o acordado no âmbito do Inova Empresa é uma realidade. Para investimento em venture capital, o orçamento foi reduzido à metade entre 2013 e 2014, caindo de R \$100 milhões para R \$ 50. Para 2016 praticamente não há recursos (apenas R\$ 219 mil reais). Os recursos para áreas estratégicas também foram reduzidos à metade entre 2013 e 2014, caindo de R\$ 1,2 bilhão para R\$ 670 milhões, aproximadamente. Houve uma recuperação em 2015, mas que não se sustentou em 2016. O montante para equalização preocupa, pois o comprometimento do crédito da Finep é o mais expressivo no Inova Empresa e incompatível com os valores previstos para subsidiar as taxas de juros. A queda do montante para subvenção econômica não foi tão expressiva como nas demais operações, mas são cerca de R 2 bilhões contratados no Inova Empresa para orçamentos anuais que não chegam a R\$ 300 milhões (Figura 2). 

2013-2015 e PLOA 2016 (valores correntes)

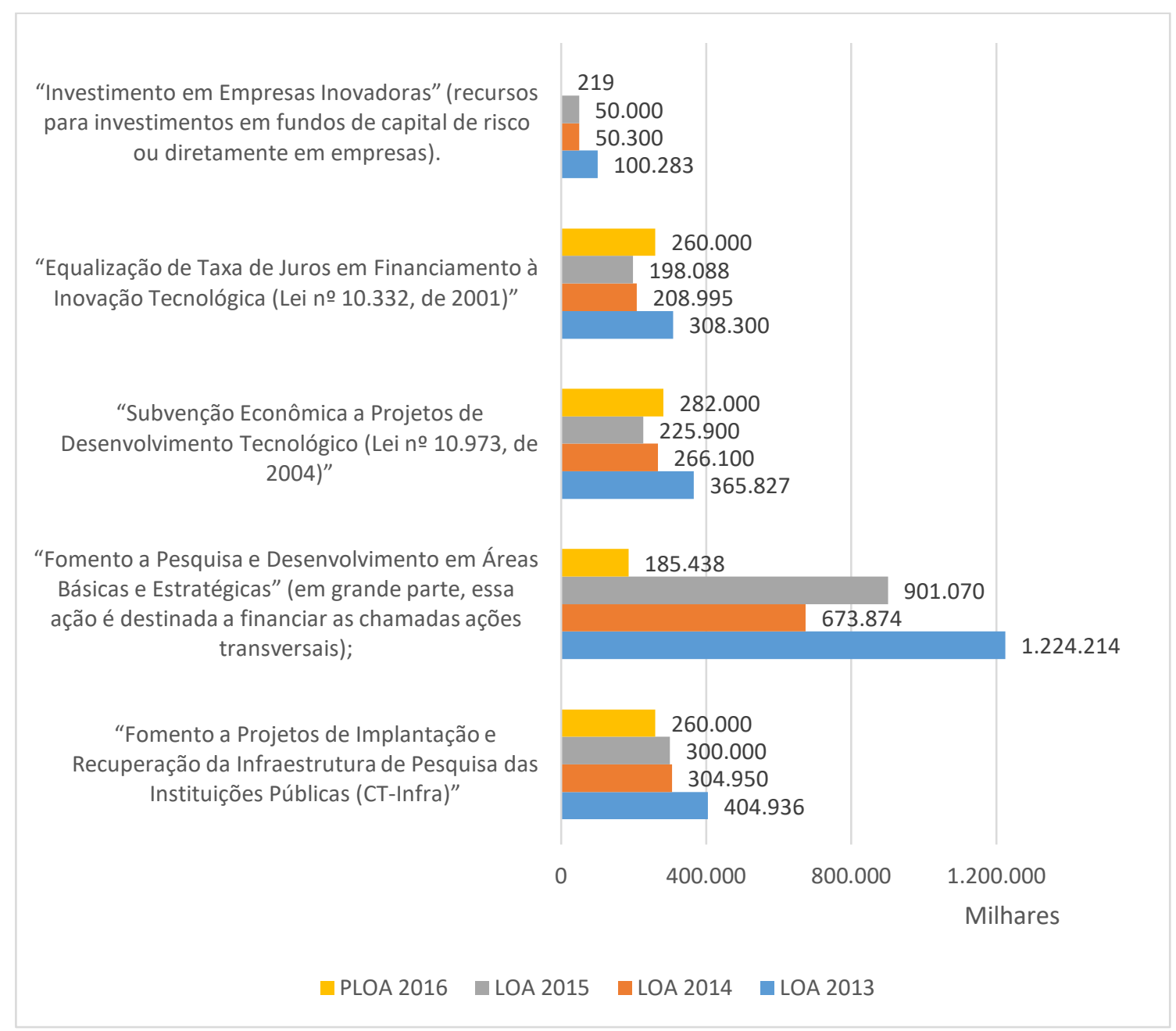

Fonte: Elaboração própria com informações do Ministério do Planejamento

O "Fomento à Pesquisa e Desenvolvimento em Áreas Básicas e Estratégicas”, com orçamento de $\mathrm{R} \$ 1,2$ bi em 2013, teve um corte de quase 50\%, ficando com dotação de $\mathrm{R} \$ 674$ milhões (2014) e R\$185,4 milhões (2016). Trata-se, como indica o nome, de P\&D em áreas estratégicas, indispensável para assegurar capacidade de geração de conhecimentos necessários para o desenvolvimento de setores relevantes da economia brasileira, da energia à agricultura, da bio à nanotecnologia. Os investimentos em infraestrutura de pesquisa das instituições públicas, que vinha sendo ampliada e recuperada, também sofreram um corte de praticamente R 100 milhões (de R\$ 404,9 milhões para R \$ 305 milhões). Em 2016 são 260 milhões, que provavelmente se refletirá no atraso do funcionamento de laboratórios e equipamentos, em alguns casos com risco até de depreciação antes mesmo de entrar em funcionamento. 


\section{Considerações Finais}

O Plano Inova Empresa foi concebido na esteira de duas experiências anteriores, o PAISS, voltado ao setor sucroenergético, e o Inova-Petro, destinado ao setor de petróleo, que buscaram dar maior organicidade no acesso dos atores aos diferentes instrumentos de financiamento à inovação - nas modalidades reembolsável, não reembolsável e venture capital/renda variável - e aos recursos das agências (Finep e BNDES).

O Inova Empresa é inovador em pelo menos três aspectos: coloca a empresa como ator principal dos projetos, permite a utilização integrada de todos os instrumentos e preocupa-se em apoiar as empresas na formatação de planos de negócios. Também inovou no sentido de alargar as fontes de financiamento, buscando envolver, de maneira coordenada, vários ministérios, agências reguladoras e instituições vinculadas ao Estado, como o Sebrae. Estabeleceu uma governança de alto nível, que deveria ter força e representatividade política para definir as linhas de ação, as prioridades executivas e coordenar de fato as ações de instituições do governo federal que na prática sempre contaram com total autonomia, inclusive em relação aos ministérios aos quais são teoricamente subordinadas. Foi ainda inovador no montante de recursos anunciados, e com tudo isto gerou bastante otimismo entre as empresas e as demais instituições de pesquisa que participariam por meio de contratos com as empresas para o desenvolvimento de atividades de P\&D com recursos não reembolsáveis.

Foi uma ação tão ousada como pouco clara, seja quanto à definição dos critérios para a seleção dos projetos seja quanto à alocação dos recursos por modalidade e quanto à própria operacionalização / execução dos projetos pelas duas agências responsáveis. Em um momento de relativa escassez de financiamento, a demanda inicial foi muito superior aos recursos ofertados, revelando o crescimento do Sistema de Inovação, a existência de demanda reprimida para financiamento de projetos com algum conteúdo de inovação e também, possivelmente, a existência de demanda por crédito em condições especiais e que parecia, pelas peças de comunicação sobre o Plano, de fácil acesso para as empresas em geral. Esta sinalização pode ter contribuído para elevar a demanda, parte da qual não se qualificava para receber recursos e foi, portanto, imediatamente desqualificada nas primeiras etapas do processo de análise. Mas certamente uma parcela não pôde ser atendida em função das limitações orçamentárias.

Ainda que não tenhamos elementos para fazer uma avaliação mais aprofundada do Plano, é possível afirmar que a crise econômica comprometerá a execução dos projetos aprovados, seja porque os recursos, nas condições contratadas, ficou mais escasso - em especial para a Finep - seja porque as próprias empresas estão colocando o pé no freio, reduzindo e/ou até mesmo cancelando projetos de investimento que haviam sido definidos no período anterior à crise, quando todas as previsões apontavam para a continuidade do crescimento econômico do Brasil. Antes mesmo do Plano Inova Empresa ser lançado já havia sinais claros de esgotamento do modelo de financiamento à inovação que fora definido em fins da década de 1990 e que deu ritmo e dinâmica ao Sistema de Inovação. A própria estrutura do Inova Empresa, assentada sobre os recursos reembolsáveis, pouco indicados para financiar inovações em geral, já refletia esses limites. Com o contexto de crise agravado, tudo indica que muitas instituições e 
empresas terão que adiar suas programações e que o governo não terá condições de cumprir os contratos, revelando mais uma vez a instabilidade e a falta de confiança de nossa economia.

\section{Referência Bibliográfica}

FINEP. Relatório de Gestão. Rio de Janeiro: Finep, 2013

Disponível em: http://www.finep.gov.br/acesso-a-informacao-externo/transparencia/114relatorios/relatorios-de-gestao/165-prestacao-de-contas-2013

FINEP. Relatórios de Gestão. Rio de Janeiro: Finep, 2014

Disponível em: http://www.finep.gov.br/acesso-a-informacao-externo/transparencia/114relatorios/relatorios-de-gestao/5263-prestacao-de-contas-2014

Ministério do Planejamento: orçamentos anuais. Disponível em http://www.planejamento.gov.br/

MCTI. Apresentação do Plano Inova Empresa, 2013

Disponível em: Senado Federal. Siga Brasil. Disponível em:

https://www12.senado.leg.br/orcamento/loa?ano=2015\&categoria=\&fase=elaboracao 